\title{
Nanotechnologies: a review of inventions and utility models. Part V
}

\author{
L.A. Ivanov ${ }^{1 *}$ (D), L.D. Xu², E.S. Bokova ${ }^{3}$ iD, A.D. Ishkov ${ }^{4}$ iD , S.R. Muminova ${ }^{5}$ (D) \\ ${ }^{1}$ Russian Academy of Engineering, Moscow, Russia \\ ${ }^{2}$ Old Dominion University, Norfolk, Virginia, USA \\ ${ }^{3}$ A.N. Kosygin Russian State University (Technology. Design. Art), Moscow, Russia \\ ${ }^{4}$ Moscow State University of Civil Engineering (National Research University), Moscow, Russia \\ ${ }^{5}$ Russian State University of Tourism and Service; Cherkizovo, Moscow region, Russia \\ * Corresponding author: e-mail: L.a.ivanov@mail.ru
}

\begin{abstract}
The article provides an abstract review of patents. The results of creative activity of scientists, engineers and specialists, including inventions in the field of nanotechnology and nanomaterials, being implemented, allow achieving a significant effect in construction, housing and community services, and related sectors of the economy. For example, the invention «A method to produce dry construction mixtures» refers to manufacturing of building materials, in particularly, to manufacture of dry construction mixtures (DCM) by the method of joint mechanoactivation of cement and dolomite, with further modification of them with carbon nanostructures (CNT). The technical result of the given method of mixing CNT and main component of dry construction mixtures cement - is that it makes possible to use microquantities (0.005\%) of CNT in DCM. That allows decreasing product cost of obtained mixture. Moreover, due to increased strength, faster hardening of materials one can reduce consumption of these mixtures. That is additional factor affecting decrease of mixture product cost.

The results obtained after application of mechanoactivation of basic mixture components were different practically by all indicators from the mixtures prepared by simple mixing. Compression strength and tensile strength increased by 10-15\%, adhesion strength increased too. Along with increasing of strength characteristics such an important indicator of DCM as air permeability has decreased. Reduction of total volume of pores in dense structure of cement matrix caused dramatic slow-up of moisture diffusion rate.

The specialists can also be interested in the following inventions in the area of nanotechnologies: a method of laser building-up welding for metal coatings, high RAP in WMA surface mixture containing nanoglass fibers, a device to apply nanoparticles of metal oxides on metal surface under normal conditions, multifunctional nanostructured additive for coatings, experimental assessment of cement mortar using nanooxide compounds, a composition for setting constructional layers of road pavements, a method to obtain composite films of nanofibers, nano-engineering of construction materials using molecular dynamics simulations, cast and self-compacting concrete mixture for cast-in-situ concrete and prefabricated reinforced units, a method to obtain photocatalyst based on nanotubular titanium dioxide et al.
\end{abstract}

KEYWORDS: nanotechnologies in construction, nanoparticles, nanostructures, nanofibers, nanomaterials.

FOR CITATION: Ivanov L.A., Xu L.D., Bokova E.S., Ishkov A.D., Muminova S.R. Nanotechnologies: are view of inventions and utility models. Part V. Nanotechnologies in Construction. 2020; 12(6): 331-338. Available from: doi: 10.15828/2075-8545-2020-12-6-331-338.

\section{INTRODUCTION}

A dvanced technologies impress people's imagination demonstrating the latest achievements (materials, methods, systems, technologies, devices etc.) that dramatically change the world. This, first of all, concerns nanotechnological inventions designed by scientists, engineers and specialists from different countries.

\section{MAIN PART}

A method to produce dry construction mixtures (RU 2735004 C1)

The invention refers to manufacturing of building materials, in particularly, to manufacture of dry construction mixtures (DCM) by the method of joint mechanoactiva-

(c) Ivanov L.A., Xu L.D., Bokova E.S., Ishkov A.D., Muminova S.R., 2020 
tion of cement and dolomite, with further modification of them with carbon nanostructures (CNT) [1]. The aim of the invention is to reduce quantity of chemical additives keeping specified parameters of physical and chemical properties and to improve mixture placeability. This task can be solved by the method which is used to produce dry construction mixtures and which comprises joint mechanoactivation of cement or materials on its base with dolomite additive $30 \%$ with the use of Hint disintegrator with further modification with carbon nanotubes in multichamber mixer-dosing plant that operates according the rule "from less to more". The optimal content of nanotubes is $0,005 \%$, at this mixing of carbon nanotubes with cement is performed in 4 stages: $0.005 \mathrm{~g}$. of CNT for $100 \mathrm{~g}$ of cement, $100 \mathrm{~g}$ of cement with CNT for $1 \mathrm{~kg}$. of cement, $1 \mathrm{~kg}$ of cement with CNT for $10 \mathrm{~kg}$ of cement, $10 \mathrm{~kg}$ of cement with CNT for $100 \mathrm{~kg}$ of cement, obtained mixture as superconcentrate is used to prepare main mixture: $100 \mathrm{~kg}$ of cement with CNT are mixed with $2000 \mathrm{~kg}$. of dry construction mixture in general mixer, then new obtained mixter is mechanically activated in Hint desintegrator, in which its grinding and homogenization are performed. The technical result of the given method of mixing CNT and main component of dry construction mixtures - cement - is that it makes possible to use microquantities $(0.005 \%)$ of CNT in DCM. That allows decreasing product cost of obtained mixture. Moreover, due to increased strength, faster hardening of materials one can reduce consumption of these mixtures. That is additional factor affecting decrease of mixture product cost.

The production of construction mixtures of this series is based on two principles, consistently complementing each other - mechanoactivation of basic mixture components and further modification of them with carbon nanostructures. Combination of two factors, determining the structure and characteristics of the final product made it possible to use maximum properties of components which are the part of dry mixtures. The results obtained after mechanoactivation has been applied to the basic mixture components were different practically by all indicators from the mixtures prepared by simple mixing. Compression strength and tensile strength increased by $10-15 \%$, adhesion strength increased too. Along with increasing of strength characteristics such an important indicator of DCM as air permeability has decreased. Reduction of total volume of pores in dense structure of cement matrix caused dramatic slow-up of moisture diffusion rate.

A method of laser building-up welding for metal coatings (RU 2735481 C1)

The invention is aimed at increasing efficiency of building-up welding and performance characteristics of iron carbon alloys, in particularly, at improving their antifriction properties, wear resistance and hardness under high and super high temperatures due to formation of layer of boron and titanium mix nitrides with specified thickness on the surface of alloys, serialized components and industrial facilities are employed in this process [2].

The scope is achieved due to the following technology: metal surface is covered with prepreg on the basis of polyamide fabric, for example, caprone sort 22059, impregnated with coking polymer composition. The fabric is destructured and active nitrogen is formed, under the temperature $140 \div 200^{\circ} \mathrm{C}$ the single macromolecule is formed, it contains simultaneously atoms of boron, titanium and nitrogen in stoichiometric ratio (two titanium atoms and one boron atom have three nitrogen atoms) and catalyst - carbon atom - when nitrides are formed. Under the temperature $1250 \div 1350^{\circ} \mathrm{C}$, caused by laser beam, prepreg is destructured giving liberate highly active atoms of boron, titanium, nitrogen and carbon which enter into reaction in porous coke forming a mixture of similar by melting temperature nitrides of titanium and boron and admixtures of heat-resistant carbides. Then the temperature is increased up to $1600 \div 1800^{\circ} \mathrm{C}$. At this coke and admixtures are distructured, and the lighter layer of solid particles, which melting temperature is about $3000^{\circ} \mathrm{C}$, rests on the iron-carbon alloy. The thickness of the protection layer depends on the number of prepreg layers. Application of the composition on the polyamide fabric is regulated by viscosity of solution of composition and the performance of impregnator.

\section{High RAP in WMA surface mixture containing nano glass fibers}

In pavement engineering, there are some challenges such as the energy consumption, emissions, and other issues. Warm Mix Asphalt (WMA) technology is considered as a possible solution in pavement construction [3]. In this invention, base binder was modified with a wax compound (Sasobit) to reduce the overall toxic emissions which also requires less energy consumption in the pavement construction operations. Bituminous Concrete mixture was used, and Bailey's method of gradation is also used. According to experiment, $3 \%$ sasobit dosage blended to the base binder shows good results, compared to other dosages that are used. A comparative study has been conducted on volumetric properties, mix stiffness, moisture susceptibility, and rutting characteristics. Mix combinations have been conducted with conventional and modified binders with different proportions of Reclaimed Asphalt Pavement (RAP) and containing Nano glass fibers. Higher percentage of RAP up to $80 \%$ and with $5 \%$ rejuvenator as vegetable oil was employed in the experiment. The experiments show that $70 \%$ RAP mix causes a big increment in terms of performance properties up to $25 \%$, comparing with the conventional mix. Reinforcement in the form of Nano Glass Fibers is con- 
sidered in order to improve the properties of RAP mixes. In the $70 \%$ RAP mixes case the performance properties have increased up to $15 \%$ with the addition of $0.3 \%$ Nano glass fibers. This invention is considered as new method for pavement construction.

A device to apply nanoparticles of metal oxides on metal surface under normal conditions (RU 2733530 C1)

The invention refers to mass-spectrometric measurements and can be widely used in solving of analytical problems in the area of organic and bioorganic chemistry, immunology, biotechnologies, criminal science, proteomics, metabolomics and medicine, metabonomics and post-translational modification. A device to apply nanoparticles of metal oxides on metal surface under normal conditions is made in the form of coaxially placed vertical capillaries. Solution (suspension of nanoparticles) is supplied in the inner metal capillary, voltage from highvoltage power source is applied to the same capillary. Droplet-free electrospraying of nanoparticles is performed from the end of the capillary under normal conditions. Inner diameter of the outer coaxial capillary is bigger than outer diameter of inner capillary. Surplus of non-sprayed solution which wets down outer shell of inner capillary, with laboratory air are pumped with air pump through gap clearance between coaxial capillaries [4].

The technical result: a metal surface of target MALDI is under room temperature, dissolvent vapour is efficiently removed from the target area of nanoparticles application, nanoparticle spots of specified size are formed on the target without templet and their borders have strict limits. Diameter of capillary through which the solution is supplied became bigger, that allows using nanoparticles with wide range of sizes. The absence of microdroplets of solution in the spraying process makes it possible to obtain applied metal oxides which are mechanically resistant to coating abrasion. All this allows conducting numerous experiments with the target.

\section{Multifunctional nanostructured additive for coatings (RU 2733526 C1)}

The invention refers to compositions of multifunctional nanostructured additive for coatings such as lacquer, paints, enamels to protect from corrosion and biofouling of underwater parts of ships and marine structures. The novelty: multifunctional nanostructured additive for coating contains, $\%$ mass.: corrosion inhibitor and organic biocide in mole ratio $0,5-2,0 / 5,0-10,0$, conducting polymer 10,0-40,0, nanoparticles of copper and zinc 2,0-10,0, aluminosilicate nanotubes - the rest up to 100 . At this aluminosilicate nanotubes are intercalated with corrosion inhibitor and organic biocide and are coated with a layer of conducting polymer with nanoparticles of copper and zinc on the surface of polymer layer [5].
Achieved technical result is intercalation of aluminosilicate nanotubes with corrosion inhibitor and organic biocide and covering of the nanotubes with a layer of conducting polymer with nanoparticles of copper and zinc on its surface. The given additive is similar to aqueous and organic ambient, it is easily dispersed and can be used in any kinds of coatings.

\section{Experimental assessment of cement mortar using nano} oxide compounds

In construction industry, cement concrete and cement mortar has been paid much attention by researchers to improve its mechanical and other features and characteristics, as such construction materials have been heavily used in construction industry world-wide. Not only mechanical strength is important, but also other characteristics and properties such as durability, chemical resistance, weather resistance, are considered important in terms of the quality of building materials. A strategy is to reduce the consumption of cement quantity through improving its characteristics/properties, or alternative materials can be considered. This strategy to reduce the consumption of cement quantity that will help natural resource sustainability as well as reducing its impact on greenhouse effect to protect natural environment. Nano materials is one of the major considerations, including nano silica, nano alumina, nano titanium oxides, although the results given by experiments are still not matured. In this invention, authors tried to find the optimum percentage of nano materials with cement mortar for maximum compressive strength. The cement sand proportion was kept 1:3, water to binder ratio was kept 0.5 , and no plasticiser was used. The influence of nano-ZnO, nano Silica, and nano Alumina on mechanical properties of cement mortar was experimentally investigated. Compressive strength tests were conducted to study the effects of nano particles on mechanical properties of cement mortar. Results of this study show that all the examined nano particles can improve durability and mechanical properties of the concrete. Nano Zinc oxide improves strength can up to $1.0 \%$, nano alumina and nano silica can be used up to $1.5 \%$ [6].

\section{A composition for setting constructional layers of road} pavements (RU $2726102 \mathrm{C1}$ )

The invention refers to road construction and can be used to set constructional layers of road pavements [7]. Composition for setting constructional layers of road pavements contains components in the following ratio, mass.\%: sand screening dust of fraction $0-5 \mathrm{~mm}-77-$ 81; Portland cement, as a mineral binder, with mineral admixtures (strength class $-32,5$, fast hardening) - 10-6; water -13 . Content of polymer composite is more than $100 \%$, mass. $\%-0,3-0,5$, which is a colloid solution of high molecular surface active compound (product of aldehyde condensation) with addition of potassium 
and sodium salts of metasilicate acid. The technical result is increased critical compressive strength and bending tension strength. This result is achieved due to formation of complex compounds in the interaction process between polymer composite and ions of liquid phase of cementpolymer system. The use of polymer composite into composition of road construction material allows rising compressive strength and bending tension strength.

Characteristics of basic materials:

1. Sand screening dust according to GOST 31424-2010 fraction $0-5 \mathrm{~mm}$

2. Mineral binder - Portland cement with mineral additives according to GOST 31108-2016: type ЦЕМ II; strength class $-32,5$; fast hardening.

3. Polymer composite in the form of colloid solution of high molecular surface active compound (product of aldehyde condensation) with addition of potassium and sodium salts of metasilicate acid (SAC is synthesized in the water under $80^{\circ} \mathrm{C}$; mass ration SAC: sodium salt:potassium salt $-1: 1: 0,5)$.

4. Water according to GOST 23732-2011.

Development of composition for road construction has been conducted according to GOST 23558-94 by combining optimal amount of binder in percents of sand screening dust mass taking into account its optimal humidity. The main criteria of evaluation of composition optimality are strength characteristics and freeze resistance coefficients.

\section{A method to obtain composite films of nanofibers} (RU 2733457 C1)

The invention refers to nanotechnology, material science and can be used in designing of membranes, substrates, filters [8]. The proposed method of obtaining films from nanofibers consists of the following operations: the solutions of two or more polymers are prepared, polymer nanofiber spinning is conducted by means of electrospinning and a film of nanofiber combination is formed. According to invention, to perform electrospinning one should use a container with a liquid in which no polymer cannot be dissolved, counter electrode is in the container. Electrospinning is performed by applying a voltage between the container and electrode and spraying independently each polymer solution from metal capillary into container with formation of polymer nanofiber suspended solids in the given liquid. Then suspended solids are mixed with homogenizer, after that film formation is performed by removing liquid. Spraying of polymer solutions into container with liquid can be performed consistently or simultaneously. Moreover, removing of the liquid can be done by precipitating nanofibers in filter or by drying. The invention allows forming films from nanofibers of polymers of different nature and chemical composition.

The technical result achieved due to this invention is an opportunity to produce films consisting of combination of different types of nanofibers, for example, nanofibers of polylactide and polysaccharose which are insoluble in one common dissolvent and which cannot be spinned from solution of polymer mixture.

The given method makes it possible to produce multicomponent films from wide range of polymers. For each polymer or polymer group a "bad dissolvent" (in which the polymer is insoluble or almost insoluble) is chosen. For example, for protein films "bad dissolvent" is alcohol - ethanol or isopropanol. Then each of polymer solution in individual dissolvent (they can be incongruent) are sprayed separately into the container with "bad dissolvent", thus nanofibers and suspended solids of these nanofibers are formed in "bad dissolvent". After that suspended solids after homogenization is used for nanofiber film spinning.

\section{Nano-engineering of construction materials using} molecular dynamics simulations

Research on molecular dynamics simulations of construction materials have been paid much attention. The purpose is to understand microscopic physical and chemical processes that is involved with the macroscopic performance of construction materials. In this invention, molecular dynamics simulations has been conducted to understand the fundamental deformation mechanism of various construction materials including concrete and cement, fiber-reinforced polymers and related bonded systems with nanoengineering approach. Using nanoengineering approach, molecular dynamics simulations reveal microscopic physical and chemical processes. The molecular information and deformation mechanisms in these construction materials and associated interfaces with other materials can be revealed through simulations. The integration of simulations in nanoscale and finite element method in macroscale is explored, it is believed that the impact of such integration is tremendous. The knowledge regarding construction materials at the nanoscale can be obtained using nano-engineering method, as such, a thorough understanding of their structural properties and mechanical behaviors can be made available. Molecular dynamics simulations especially the understanding of structures and interactions are promising for construction materials improvement and upgrading [9].

Cast and self-compacting concrete mixture for cast-in-situ concrete and prefabricated reinforced units (RU 2725559 C1)

The invention refers to construction materials, in particularly, to cast and self-compacting concrete mixture and can be used in production of cast-in-situ concrete and prefabricated reinforced units and articles of widespread use, including high-density reinforcement structures as well as massive concrete and reinforced concrete structures and buildings with increased crack- 
resistance, low heat radiation, high rate of hardening, specified strength, water permeability, frost resistance and durability [10].

Cast and self-compacting concrete mixture for castin-situ concrete and prefabricated reinforced units comprises nanocement of one of the following type 30, 35, 45,55 , building sand, ballast stone, water, ballast stone with fraction 5-10 $\mathrm{mm}$ and additionally - stone screening dust with fraction $2-5 \mathrm{~mm}$ and following ratio of components, mass.\%: the mentioned nanocement $12-20$; building sand 20-35; stone screening dust with fraction 2-5 mm 15-21; ballast stone with fraction 5-10 mm 20-29; water - the rest. Cast and self-compacting concrete mixture in which specific surface of nanocement is $600-900 \mathrm{~m}^{2} / \mathrm{kg}$, also contains antifreeze admixture, its quantity is $1-2$ mass. $\%$. The technical result - high consistency of concrete mix and preservation of it for one or two hours with minimal water content.

Today production of cast and self-compacting concrete mixtures is considered to be the most promising area in concrete industry as it makes possible to deliver and cast concrete mixtures which will fill all space of reinforcement.

A method to obtain photocatalyst on the basis of nanotubular titanium dioxide (RU 2732130 C1)

The invention refers to electrochemical technology for production of titanium compounds, in particularly, to technology of obtaining nanotubular titanium dioxide $\left(\mathrm{TiO}_{2}-\mathrm{NT}\right)$ with increased photocatalytic activity by means of anodizing and can be used in photocatalytic treatment of air from organic pollutants [11].

Titanium dioxide is a promising material as there is a need to develop green technologies, i.e. eco-friendly technologies. Moreover, titanium dioxide is a material that could clean up environment from pollutants. Its photocatalytic and electrophysical properties are unique, that fact makes it possible to purify water and air, to create self-cleaning coatings, degrade bacteria, to produce solar elements on the basis of it, lithium-ion accumulators as well as to obtain hydrogen in water photolysis process. Physical characteristics of anodized titanium dioxide depend on structural and geometrical parameters which can be varied when determining proper conditions for anodizing process.

The use of corrosion steel allows prolonging operating time as well as significantly decreasing photocatalyst cost. The process time has been 9 times shortened due to combination of anodizing conditions: chemical composition of electrolytic solution, cathode material, voltage and environment temperature. The initial roughness of industrial titanium metal paper BT1-0 is acceptable to obtain even oxide layer of titanium dioxide nanotubes, therefore there is no need to polish mechanically titanium when preparing it for anodizing.
Eco-Building Material of Styrofoam Waste and Sugar Industry Fly-ash Based on Nano-Technology

The construction material manufacturing directly affect environmental degradation that results in global warming and climate change. In addressing this, the concept of sustainable green construction, especially with concrete constituent materials modification has been proposed. Research and development of green construction material has attracted much attention. In this invention, industrial waste of Styrofoam is applied to manufacturing concrete which offers features such as light weight and good resistance against seepage. The fly ash's intended use is to be used as cement substitute material, thus the use of cement in the concrete mix can be reduced. The use of fly ash from sugar mills TrangkilPati, Indonesia, provides proof of increasing the compressive strength of lightweight concrete. In this invention, nano technology concept is applied to improve the quality of foam-brick performance. The advantages of using Styrofoam include aerated light-weight concrete and fly ash usage forming materials, offering eco building material. The benefits include: use of waste materials reducing manufacturing cost, increase the value of industrial waste, reducing earthquake disaster relief efforts as less relief work required due to lighter weight of the structure, increasing structure residential safety during disaster, and suitable for residential buildings in the earthquake zone [12].

Alloying element for preparation of composite materials on the basis of aluminum or aluminum alloys and a method to obtain alloying element (RU 2734316 C9)

The invention refers to alloying elements for preparation of composite materials on the basis of aluminum or aluminum alloys and can be used in non-ferrous industry to produce strengthened aluminum materials by means of mould technologies. Composite materials on the basis of aluminum are widely used as they are extra strong, resistant to friction and high temperatures. The properties of aluminum composite materials depend on the size of filler dispersed in it. Filler of smaller sizes, in particularly, carbon nanotubes provides better material characteristics, however, it is very difficult to disperse such filler as its size is too small [13].

The invention solves a problem of creation of alloying element for aluminum and aluminum alloys, that will make possible to produce composite materials on the basis of aluminum or aluminum alloys with carbon nanotubes evenly distributed in them. The imposed task can be solved in the following way: the proposed alloying element for aluminum and aluminum alloys comprises aluminum and carbon nanotubes surface of which contains adsorbed gases in such a quantity that mass ratio of the given nanotubes and adsorbed gases is less than 100. One should note that at least some nanotubes are 
located in aluminum volume in such a way they have no contact with environment.

The proposed alloying element may contain singlewalled, and/or double-walled, and/or multi-walled carbon nanotubes. Alloying element can be made in the form of metal cast with carbon nanotubes inside. Also, alloying element can be metal pressed, rerolling feed or stamped bank with carbon nanotubes inside. Composition of alloying element can contain at least one of the following metal: copper, and/or zinc, and/or magnesium, and/or lead.

The specialists can also be interested in the following inventions related to nanotechnologies:

- A method to obtain reinforced nanocomposite with additional properties [14].

- A plant for synthesis of carbon-containing nanomaterials [15].

- A method to produce nanoporous ceramics on the basis of mullite [16].

- Graphene microspheres in the form of paper ball, composite material of such microsphere and a method to produce such microspheres [17].

- A method to obtain modified carbon nanotubes [18].

- A method to obtain electroluminescence mixed leadhaloid perovskite materials with high phase stability [19].

- Tools for detection of nuclear composition of atmospheric emissions of nuclear atomic power stations [20].
- A method to obtain heat stable microporous coating based on mixed titanium-silica oxide [21].

- Luminescence sensor of heavy metal ion concentration in water (mainly for cobalt) based on triple composition quantum boxes [22].

- Various aerosol filters for neutron activation analysis [23].

- Modified polymer composition and a method to obtain it [24].

- Gunn-effect diode on the basis of wire-type nanocrystals of gallium nitride [25].

- Heat insulating material based on aerogel with capability to introduce nanomaterials into final product [26].

- A method to produce composite materials based on ti-b-fe, modified with nanosize particles AIN [27].

- Fibroporous structures of polyurethane solutions for manufacturing [28].

\section{CONCLUSION}

One of the most challenging tasks the economy of every country face is to increase industrial competitiveness through technological upgrade. From the side of the state and companies the principal object to control in this process are the people and enterprises dealing with introduction of inventions and new technologies.

Therefore, we hope that the information published in this section will be in demand and useful for specialists.

\section{REFERENCES}

1. Krivtsov E.E., Golik A.M. A method to produce dry construction mixtures. Russian Federation Patent 2735004. 27.10.2020.

2. Sychev A.P., Kolesnikov V.I., Lapitsky V.A. et al. A method of laser building-up welding for metal coatings. Russian Federation Patent 2735481. 03.11.2020.

3. Rochishnu E., Ramesh A., Ramayya V. V. Sustainable pavement technologies-performance of high RAP in WMA surface mixture containing nano glass fibers. Materials Today: Proceedings. 2020.

4. Podolskaya E.P., Kelzieva O.A., Krasnov N.V. et al. A device to apply nanoparticles of metal oxides on metal surface under normal conditions. Russian Federation Patent 2733530. 05.10. 2020.

5. Vinokurov V.A., Glotov A.P., Guschin P.A. et al. Multifunctional nanostructured additive for coatings. Russian Federation Patent 2733526. 02.10.2020.

6. Kantharia M., Mishra P. K., Jani S., Trivedi M. K. Experimental assessment of cement mortar using nano oxide compounds. Materials Today: Proceedings. 2020; 29: 456-461.

7. Dabizha O.N., Konovalova N.A., Pankov P.P et al. A composition for setting constructional layers of road pavements. Russian Federation Patent 2726102. 09.07.2020.

8. Klinov D.V., Moskalets A.G. A method to obtain composite films of nanofibers. Russian Federation Patent 2733457. 01.10.2020.

9. Lau D., Jian W., Yu Z., Hui D. Nano-engineering of construction materials using molecular dynamics simulations: Prospects and challenges. Composites Part B: Engineering. 2018;143: 282-291.

10. Bikbau M.Yu., Khusnutdinov A.M. Cast and self-compacting concrete mixture for cast-in-situ concrete and prefabricated reinforced units. Russian Federation Patent 2725559. 03.07.2020. 
11. Valeeva A.A., Dorosheva I.B., Vokhmintsev A.S. et al. A method to obtain photocatalyst based on nanotubular titanium dioxide. Russian Federation Patent 2732130. 11.09.2020.

12. Setyowati E. Eco-building material of styrofoam waste and sugar industry fly-ash based on nano-technology. Procedia Environmental Sciences. 2014;20: 245-253.

13. Predtechensky M.R., Khasin A.A., Alekseev A.V. Alloying element for preparation of composite materials on the basis of aluminum or aluminum alloys and a method to obtain alloying element. Russian Federation Patent 2734316. 18.11.2020.

14. Ivanov L.A., Razumeev K.E., Bokova E.S., Muminova S.R. The inventions in nanotechnologies as practical solutions. PartV. Nanotechnologies in Construction. 2019; 11(6): 719-729. Available from: doi: 10.15828/2075-85452019-11-6-719-729.

15. Vavilov E.S. A plant for synthesis of carbon-containing nanomaterials. Russian Federation Patent 2732842. 23.09.2020.

16. Morozova L.V. A method to produce nanoporous ceramics on the basis of mullite. Russian Federation Patent 2737298. 26.11.2020.

17. Gao Ch., Chen Ch., Han I. Graphene microspheres in the form of paper ball, composite material of such microsphere and a method to produce such microspheres. Russian Federation Patent 2734476.16.10.2020.

18. Ivanov L.A., Bokova E.S., Muminova S.R., Katuhin L.F. Nanotechnologies: a review of inventions and utility models. Part I. Nanotechnologies in Construction. 2020; 12(1): 27-33. Available from: doi: 10.15828/2075-8545-202012-1-27-33.

19. Pushkarev A.P., Anoshkin S.S., Lyashenko T.G., Makarov S.V. A method to obtain electroluminescence mixed lead-haloid perovskite materials with high phase stability. Russian Federation Patent 2733933. 08.10.2020.

20. Vasyanovich M., Vasilyev A., Ekidin A., Kapustin I., Kryshev A. Special monitoring results for determination of radionuclide composition of Russian NPP atmospheric releases. Nuclear Engineering and Technology. 2019; 51(4): 1176-1179.

21. Gorshkov A.A., Avdin V.V., Morozov R.S. A method to obtain heat stable microporous coating based on mixed titanium-silica oxide. Russian Federation Patent 2733936. 08.10.2020.

22. Dubovik A.Yu., Baranov A.V., Kurshanov D.A. Luminescence sensor of heavy metal ion concentration in water (mainly for cobalt) based on triple composition quantum boxes. Russian Federation Patent 2733917. 08.10.2020.

23. Zuyev S.V., Afonin A.A., Burmistrov Y.M., Konobeevski E.S., Mordovskoy M.V., Ponomarev V.N., Solodukhov G.V., Kapustin I.A., Pletnikov E.V. Studying the possibility of using different aerosol filters for neutron-activation analysis. Bulletin of the Russian Academy of Sciences: Physics. 2019; 83(4): 445-448.

24. Lependin S.V., Soikin A.S. Modified polymer composition and a method to obtain it. Russian Federation. Patent 2737375. 27.11.2020.

25. Mozharov A.M. Gunn-effect diode on the basis of wire-type nanocrystals of gallium nitride. Russian Federation Patent 2733700. 06.10.2020.

26. Ivanov L.A., Ishkov A.D., Pisarenko Zh.V., Wang Q., Prokopiev P.S. Nanotechnologies: a review of inventions and utility models. Part IV. Nanotechnologies in Construction.2020;12(5): 275-284. Available from: doi: 10.15828/20758545-2020-12-5-275-284.

27. Bolotskaya A.V., Mikheev M.V., Bazhin P.M., Stolin A.M. A method to produce composite materials based on ti-b-fe, modified with nanosize particles AIN. Russian Federation Patent 2737185. 25.11.2020.

28. Vasyanovich M., Vasilyev A., Ekidin A., Kapustin I., Kryshev A. Special monitoring results for determination of radionuclide composition of Russian NPP atmospheric releases. Nuclear Engineering and Technology. 2019; 51(4): 1176-1179.

\section{INFORMATION ABOUT THE AUTHORS}

Leonid A. Ivanov, Cand. Sci. (Eng.), Vice President of the Russian Academy of Engineering, Member of the International Journalist Federation; Moscow, Russia, ORCID: https://orcid.org/0000-0001-9513-8712, e-mail: L.a.ivanov@mail.ru

Li D. Xu, Ph.D., Prof., Old Dominion University, of Information Technologies \& Decision Sciences Department; Institute of Electrical and Electronics Engineers (IEEE), Norfolk, Virginia, USA, e-mail: LXu@odu.edu

Elena S. Bokova, Dr. Sci. (Eng.), Prof., Department of Chemistry and Technology of Polymers and Nanocomposites, A.N. Kosygin Russian State University (Technology. Design. Art), Moscow, Russia,

ORCID: https://orcid.org/0000-0001-7769-9639, e-mail: esbokova@ya.ru 
Aleksandr D. Ishkov, Cand. Sci. (Psychology), Associated Professor, Moscow State University of Civil Engineering (National Research University), Head of the Department of Social, Psychological and Legal Communications, Moscow, Russia, ORCID: http://orcid.org/0000-0002-1709-0175, e-mail: aishkov@gmail.com

Svetlana R. Muminova, Cand. Sci. (Eng.), Assistant Professor, Russian State University of Tourism and Service; Cherkizovo, Moscow region, Russia, ORCID:https://orcid.org/0000-0001-5236-607X, e-mail: it.rguts@mail.ru

All authors declare the absence of any competing interests.

Received: 03.11.2020.

Revised:07.12.2020.

Accepted:09.12.2020. 